Article

\title{
Hosting Capacity Calculation Deploying a Hybrid Methodology: A Case Study Concerning the Intermittent Nature of Photovoltaic Distributed Generation and the Variable Nature of Energy Consumption in a Medium Voltage Distribution Network
}

\author{
Ezequiel Junio Lima ${ }^{1, *, t, \neq(\mathbb{0})}$ and Luiz Carlos Gomes Freitas ${ }^{2, \ddagger(1)}$ \\ 1 Department of Electrical and Electronic, Federal Center for Technological Education of Minas Gerais, \\ Curvelo 35790-636, MG, Brazil \\ 2 Faculty of Electrical Engineering, Federal University of Uberlândia, Uberlandia 38408-100, MG, Brazil; \\ lcgfreitas@ufu.br \\ * Correspondence: ezequiel@cefetmg.br \\ † Current address: 900, Raymundo Mattoso St., Curvelo 35790-636, MG, Brazil. \\ $\ddagger$ These authors contributed equally to this work.
}

check for updates

Citation: Lima, E.J.; Freitas, L.C.G. Hosting Capacity Calculation Deploying a Hybrid Methodology: A Case Study Concerning the Intermittent Nature of Photovoltaic Distributed Generation and the Variable Nature of Energy Consumption in a Medium Voltage Distribution Network. Energies 2022, 15, 1223. https://doi.org/10.3390/ en15031223

Academic Editors: Gian Giuseppe Soma and Antonio Rosato

Received: 25 November 2021

Accepted: 25 January 2022

Published: 8 February 2022

Publisher's Note: MDPI stays neutral with regard to jurisdictional claims in published maps and institutional affiliations.

Copyright: (C) 2022 by the authors. Licensee MDPI, Basel, Switzerland. This article is an open access article distributed under the terms and conditions of the Creative Commons Attribution (CC BY) license (https:// creativecommons.org/licenses/by/ $4.0 /)$.

\begin{abstract}
The main methods employed for Hosting Capacity (HC) calculations are basically classified into deterministic, stochastic and time series. In this scenario, the authors herein propose a hybrid methodology, which shows efficiency and ease of implementation. Besides the method presented, it is also calculated a hosting capacity of a real feeder which was modeled and analyzed taking into consideration variations in load and power injected by distributed generation sources. The proposed hybrid method deploys just one time series with the feeder power demand data, which are easily obtained from the feeder's origin substation. Low voltage loads were modeled by the ratio between their maximum demands and the feeder maximum demand, making easier to start up the grid model implementation. Hence, the advantages of the proposed methodology can be summarized in: (a) easy to obtain the input parameters; (b) agility in implementing the study; (c) higher processing speed and (d) results consistent with the time series method. Finally, in view of the advantages and obtained results, the proposed hybrid methodology shows itself as a promising and attractive tool for the studies of hosting capacity by the utilities.
\end{abstract}

Keywords: hosting capacity; solar energy; solar power integration; distributed energy resources; power quality; electricity distribution; distribution-system planning

\section{Introduction}

Over the last ten years, photovoltaic energy has shown potential to become one of the most prominent sources of electric energy in the world, through its robust and continuous growth, even during periods of financial and economic turmoil. The International Energy Agency (IEA) estimates that solar energy will become one of the main sources of energy by 2050 and will contribute with around $11 \%$ of world energy generation [1].

Brazil is following this worldwide tendency and presents itself as a promising market. According to the national energy balance of 2019, there was an increase in the generation of electric solar energy of $316.1 \%$ from the year 2017 to 2018, which represented a jump from $832 \mathrm{GWh}$ to $3461 \mathrm{GWh}$ [2]. Through such, the participation of the solar energy on the Brazilian electric energy grid, in 2019, arrived at 1\% of its total [3] and in the December of 2021 to $2.4 \%$ [4]. If one considers both distributed generation (DG) and centralized generation (CG), also until the December of 2021, Brazil registered an installed operational power of $12.2 \mathrm{GW}$ [4]. 
Aligned with this panorama and paying close attention to the market, the Brazilian National Agency of Electric Energy (ANEEL) released, in 2016, the so-called No.001/2016 Priority R\&D Project for Efficient and Strategic Energy: "Energy Efficiency and Minigeneration at Public Institutions of Higher education", aimed at creating partnerships between Energy Utilities and Public Universities. The objective behind the public notice was to ease the insertion of photovoltaic generation onto the Brazilian energy grid and onto the public sector, while seeking to assess the economic viability of local generation and its impacts on distribution systems [5].

Therefore, on the one hand, one has the growth of the renewable photovoltaic source that brings benefits to the consumer and contributes to: security in the supply of electric energy; tariff moderateness; decrease in environmental impact of the electric energy sector and a reduced dependency on hydropower generation. On the other, new worries are put on utilities concerning the dissemination of GD on their network, along with the impacts that the increase in photovoltaic generation can bring.

In their study, Karimi et al. [6] point out that due to the growth in the popularity of photovoltaic plants (PVPs), it becomes necessary to perform studies into the possible impacts to the quality of the "electric energy product", along with the coordination and operation of the protection provided to distribution networks.

In this manner, the studies from this area, which assess problems arising from the connection of distributed generation onto the grid, use the hosting capacity (HC) and/or sustainability limit to define the maximum capacity of the photovoltaic solar energy source that can be connected to a particular network (in a given location; on a given feeder or onto a network as a whole), without contravening any regulatory parameter, i.e., without resulting in unacceptable parameters of reliability, in terms of energy quality and/or security $[7,8]$.

According to EPRI [9], the concept of hosting capacity (HC) is not new, but its application is becoming more widespread, as the market needs a wide-ranging approach in order to understand the impacts from DG. In light of such, various methods for determining hosting capacity have been developed over recent years [10-13], which has resulted in an intense debate on "which", "how" and "when" such methods should be used.

In this aspect, the studies reported in $[9,11,12,14]$ present the main methods employed for the calculation of the Hosting Capacity and classify such methods basically into deterministic, stochastic and time series. One can still find other methodologies based on optimization, neural networks, genetic algorithms and deep learnig [14-16]. These methods, however, are more related PV Hosting Capacity Enhancement in LV/MV networks with high photovoltaic penetration and are beyond the scope of this paper. In the following session, a succinct definition is given for each of these methods, in order to highlight the main indicators that are able to determine the choice and application of each methodology (see Table 1). Faced with this scenario, the authors herein propose a hybrid methodology, which shows efficiency and ease of implementation. In order to validate the proposed method the study results are presented, which had the objective of determining the hosting capacity of a real feeder situated in the municipal of Poços de Caldas, Brazil, from the utility DME Distribution (DMED). The referred to feeder was modeled and analyzed taking into consideration variations in load and power injected by DG sources onto the different buses that make up the system. 
Table 1. Comparison between methods for calculating HC.

\begin{tabular}{|c|c|c|c|c|c|}
\hline Characteristic & Ref. & Deterministic & Stochastic & Time Series & $\begin{array}{c}\text { Proposed } \\
\text { Hybrid } \\
\text { Method }\end{array}$ \\
\hline Obtainment of input parameters & {$[9,10]$} & Easy & Complex & Moderate & Moderate \\
\hline Implementing the study & {$[9-12]$} & Easy & Complex & Complex & Moderate \\
\hline $\begin{array}{l}\text { Supports the processing } \\
\text { of uncertainties }\end{array}$ & {$[11-14]$} & No & Yes & Yes & Yes \\
\hline Simulated Scenario & {$[11-14]$} & $\begin{array}{l}\text { Worst } \\
\text { possible } \\
\text { case }\end{array}$ & $\begin{array}{c}\text { Realistic } \\
\text { scenario } \\
\text { (millions of } \\
\text { simulations) }\end{array}$ & $\begin{array}{l}\text { Realistic } \\
\text { scenario } \\
\text { (based on } \\
\text { measure- } \\
\text { ments) }\end{array}$ & $\begin{array}{c}\text { Realistic } \\
\text { scenario } \\
\text { (based on } \\
\text { measure- } \\
\text { ments) }\end{array}$ \\
\hline Maintains temporal relationship between quantities & {$[11-13,17]$} & Yes & No & Yes & Yes \\
\hline Processing speed & {$[11-14,16]$} & Fast & Moderate & Slow & Moderate \\
\hline Simulation time & {$[12,14,16]$} & Fast & Slow & Slow & Moderate \\
\hline Computational effort (processing) & {$[11-14,16]$} & Low & High & High & Moderate \\
\hline Scalability of the methodology & {$[11-14,16]$} & Easy & Complex & Complex & Moderate \\
\hline Interpretation of results & {$[11,12]$} & Easy & Complex & Easy & Easy \\
\hline
\end{tabular}

\section{Main Methods for Determining HC}

\subsection{Deterministic Method}

Deterministic methods apply known and fixed input data to a distribution network model, for analyzing the impacts from inserting photovoltaic solar energy [12]. As such, their implementation is simple and the distribution network is modeled using active power $(\mathrm{P})$, reactive power $(\mathrm{Q})$, series line impedance $(\mathrm{Z})$ and load models with impedance, current or constant power. These methods assess the system based on scenarios and normally consider the worst case possible to evaluate the extreme impact of predefined parameters, such as the input of a photovoltaic plant $[9,12,18]$.

The method employs the traditional power flow analysis as a tool for the calculations. Their implementation is considered as simple, given that analyzes employing power flow is the fundamental analysis resource used by a majority of energy utilities [12]. In the results, a general and prompt view is presented of the network performance with a distributed generation (DG) connection. As fixed values are assumed, the intermittent nature of photovoltaic DG is not considered and as such, the hosting capacity obtained is an estimate for the worst case scenario. Consequently, the impact tends to be overestimated and the hosting capacity underestimated [11].

\subsection{Stochastic Methods}

Upon modeling a distribution network with DG, it is common to encounter uncertain parameters. As for example, the production of photovoltaic energy from a particular PVP is uncertain, as it depends on solar irradiation, which in turn is influenced by changes in climatic conditions. Apart from these uncertainties, the power demand from consumers, the size of the PVP that will be added to the grid, their respective geographic location and many other technical and constructive characteristics are often unknown [12,18-20]. Therefore, stochastic methods consider the possibility of occurrence and the variations present on the distribution network amidst these uncertainties and culminate into a probabilistic power flow.

Accordingly, for data entry of this calculation method, it is necessary to define which uncertainties will be considered and which statistical probability density function give the best representation (for example: Uniform, Poisson, Gaussian or Binomial among others). Consequently, the output variables will also be given by a probability density function. The evaluation and interpretation of these results is not trivial and, as such, the determination of the hosting capacity presents a degree of difficulty [12,21,22]. 
According to Kharrazi, Sreeram and Mishra [18], the stochastic technique is that which best models the uncertainties and randomness of the network. However, it requires a large amount of computational time and effort, as the network model or number of uncertainties considered increases [17,18].

The collaborators Mulenga, Bollen and Etherden [12], claim that if the objective of the study is the dimensioning of the network, there will be little value aggregated in considering a large quantity of scenarios with moderate conditions, i.e., it would be sufficient to analyze only the worst case. In light of the aforementioned, stochastic methods are not always necessary.

\subsection{Time Series Method}

Time series methods use real system measurements as input for hosting capacity calculations. In this way, "load shapes", "photovoltaic energy production shapes", "voltage profile of the feeder", among others, are used to simulate the grid at each desired moment.

As these use data measured in terms of time, the method allows for correlations to be made between variables, as for example, the increase in temperature with the increase in energy consumption and the increase-or reduction-in photovoltaic energy production. This method also allows for a realistic view of the behavior concerning a network with DG, since photovoltaic energy production and energy consumption-on the part of users-are characteristics that are naturally variable over time.

The implementation for this type of method is complex as it requires a lot of data measurements (data that will make up time series) for creating behavior analysis. In cases where does not exists a historical data series, one can alternatively consider the use of stochastic processes for creating the data time series over a longer period of time, such as in the following methods: autoregressive (AR), autoregressive moving average (ARMA) and autoregressive integrated moving average (ARIMA) [12].

Attention should also be paid to which parameter you wish to use for the studies, since this will directly influence the temporal resolution of data sampling rate. For instance, a resolution of $15 \mathrm{~min}$ may be sufficient for long-term voltage variations, however, short-term voltage variations may require a temporal resolution of one minute-or less-and as such represent a computational challenge as the time span for data collection increases.

\subsection{Proposed Hybrid Method}

Through an analysis of each method, it appears that the deterministic method for the calculation of $\mathrm{HC}$, although fast and easy to use, does not take into account uncertainties such as photovoltaic energy production, consumer demand, the size of PVP, etc. In turn, the stochastic method deals with uncertainties, but loses the temporal relationships of the studied quantities, thus preventing the performing of protection coordination studies or the correlation between the production and demand of energy.

Finally, the method that employs time series deals with the variations in photovoltaic energy production, as well as with the variations in power demand from consumers, although this demands historical data in order to construct the time series, in a way that allows for the behavioral analysis of the loads.

In order to obtain a hybrid method, the option was made to combine the deterministic and time series methods, with the aim of getting the best from both. To this end, the feeder modeling should take into consideration the temporal variations of the loads and the injection of energy from the PVP, as would be done in the typical time series method. The difference, however, resides in how these load shapes are collected directly from the feeder's substation, since it is common for the energy utilities to install meters and loggers in the medium voltage feeders. The way of data collection, by itself, already represents an advantage over the time series method due to the ease of obtaining it.

Low voltage loads were modeled by the ratio between their maximum demands and the maximum demand of the feeder. That is, the loads are defined in a deterministic way 
and each load contributes proportionally to the feeder's power demand, as shown in the Equations (1) and (2):

$$
\begin{gathered}
\alpha_{1} \cdot D_{F}(t)+\alpha_{2} \cdot D_{F}(t)+\cdots+\alpha_{n} \cdot D_{F}(t)=D_{F}(t) \\
\alpha_{i}=\left.\frac{\max \left(D_{L_{i}}\right)}{\max \left(D_{F}\right)}\right|_{i=1,2, \cdots, n}
\end{gathered}
$$

were $D_{F}$ is the feeder's power demand; $D_{L}$ is the load's power demand; $\alpha_{i}$ is the load $i$ contribution coefficient and $n$ is the number of loads.

In this way, the system can be simulated according to the typical behavior of the network, thus creating more realistic scenarios. The processing speed and computational time will be an intermediate value between the two. Its implementation is simpler, as it executes only the cases of interest to the study in question.

Therefore, it is within this context that this article seeks to contribute to the theme, by applying the proposed hybrid methodology into the hosting capacity calculation of a real feeder, located in municipal of Poços de Caldas, MG, of the energy utility DME Distribution (DMED).

\section{Model of the System in Question}

The system in question is composed of a medium voltage radial feeder, a solar photovoltaic power plant (PVP) and various loads that are noted from the single-line diagram presented in Figure 1. The feeder circuit 19, supplies the South Zone of the municipal of Poços de Caldas, and which extends for $22 \mathrm{~km}$ and provides energy for 7084 consumer installations (until the moment of writing). In addition, the feeder operates at a nominal voltage of $13.8 \mathrm{kV}$ that starts from a transformer of $20 \mathrm{MVA}$ from the substation $\left(S E_{P C 3}\right)$. The construction of the load models and of the PVP is explained in the following subsections, along with information concerning the components of the model (cables, capacitors etc.), which were provided by the utility DME Distribution.

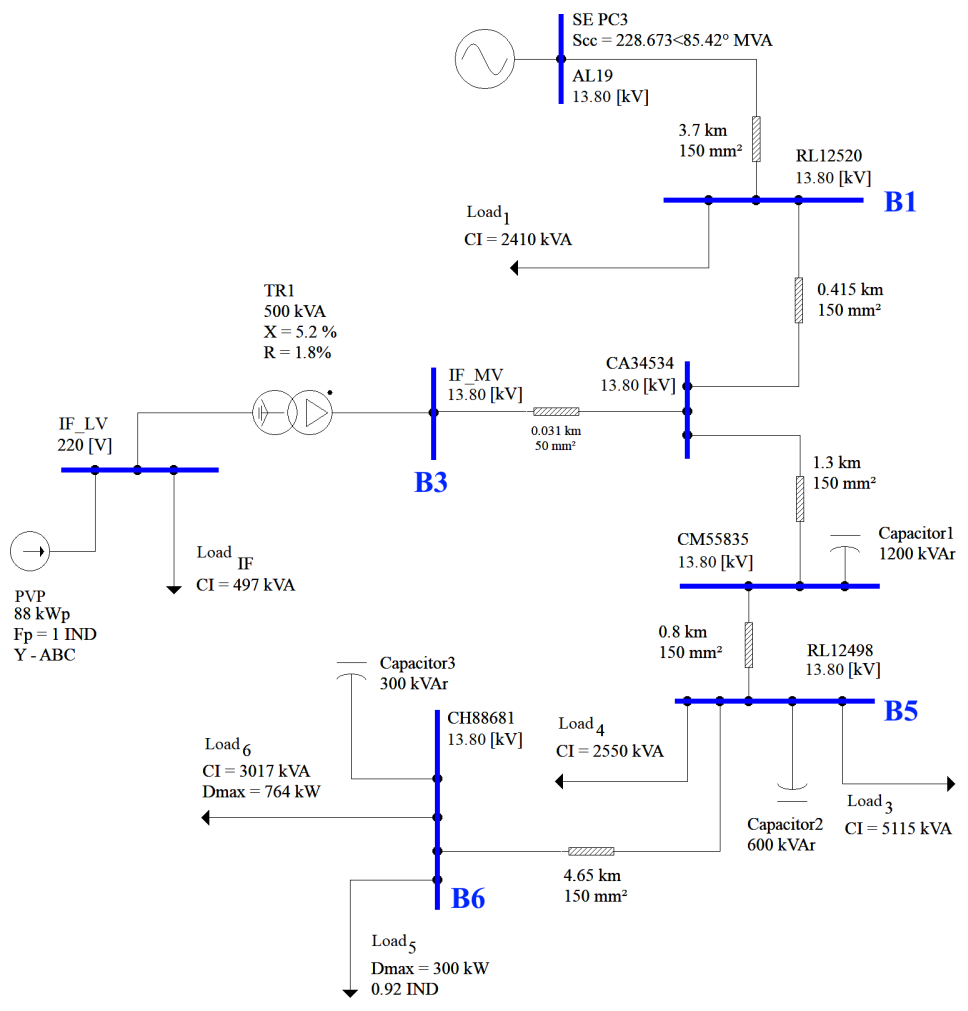

Figure 1. Feeder 19 single line diagram. 
The modeling in the proposed hybrid methodology was performed through the commercial software SSEP ${ }^{\circledR}$ (acronym for Electric Power Systems Simulator, in Portuguese) version 4.0.0.25 [23]. The program uses domain frequency techniques for the solution of conventional and harmonic load flows of electrical power systems. For comparison and validation purposes, the system was also modeled using the software OpenDSS ${ }^{\mathrm{TM}}$ [24] which was in charge of time series methodology calculations.

\subsection{Linear Loads}

According to Kagan, Oliveira and Robba [25], from among all the components that make up the electric system, those that possibly present the greatest challenge in terms of modeling are the loads. In light of this aspect, for their representation, it is common to use concentrated loads at given points of the network, uniformly distributed loads, loads represented by maximum demand and loads represented by typical loads shapes.

Two distinct ways were then adopted for loads modeling. In the model where the time series technique was used, low voltage loads were represented by typical loads shapes. In the model used for the hybrid technique, low voltage loads were represented by the maximum demand, according to Equation (1). Table 2 shows the contribution coefficients values for each load, calculated by the Equation (2). In both models, loads were grouped according to the neighborhoods served, as shown in Figure 2.

Table 2. Loads contribution coefficients of the proposed hybrid method.

\begin{tabular}{ccccccc}
\hline & Load $_{1}$ & Load $_{\mathbf{2}}$ & Load $_{3}$ & Load $_{4}$ & Load $_{5}$ & Load $_{\mathbf{6}}$ \\
\hline$\alpha_{i}$ & $10.3 \%$ & $1.1 \%$ & $33.7 \%$ & $26.9 \%$ & $10.1 \%$ & $17.9 \%$ \\
\hline
\end{tabular}

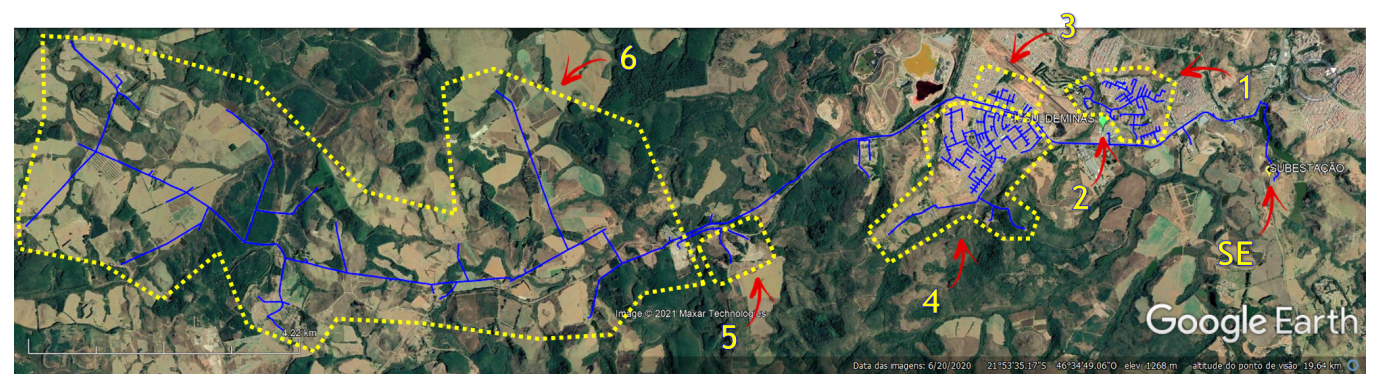

Figure 2. Google Earth view of Feeder 19 and its loads groups.

The behavior of the medium voltage network was modeled through the load curve with data collection performed by a demand and energy logger, installed at the substation $\left(S E_{P C 3}\right)$. This kept a record of the voltage and current values, energy and demand for the period of January to December of 2019, with an integration interval of $5 \mathrm{~min}$.

The results compiled for power demand are represented in Figure 3. Noteworthy here is that the behavior of this curve is typical of consumers with a predominantly residential profile, as is indicated in studies [26-28]. 


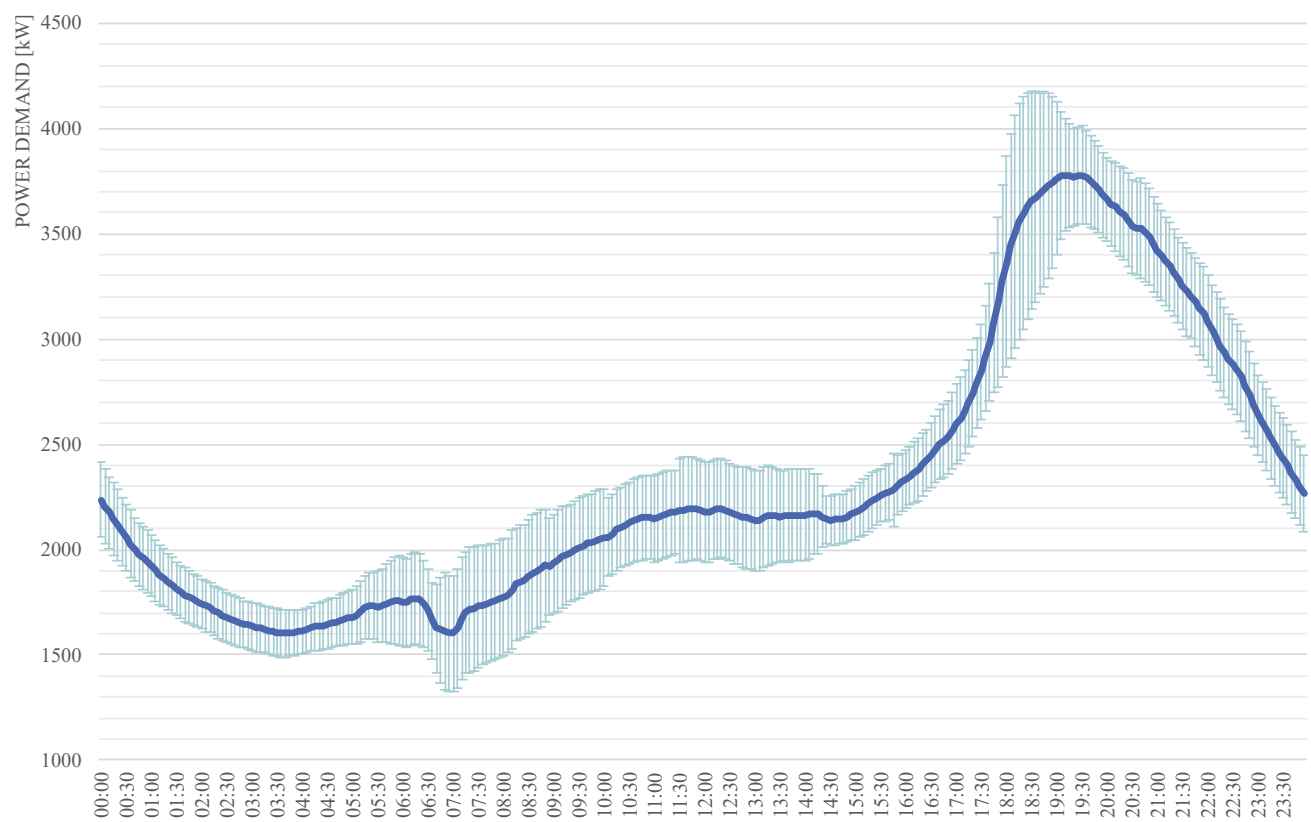

Figure 3. Average daily power demands between January and December 2019 and associated standard deviation of Feeder 19.

\subsection{Photovoltaic Power Plant}

The distributed generation (DG) inclusion into feeder 19 will be based on the photovoltaic plant (PVP) that already exists on the feeder, located at the Poços de Caldas campus of IFSULDEMINAS, installed since January 2017, with $88 \mathrm{kWp}$ of nominal power.

According to Sauthier et al. [29], a recurring problem in the modeling of photovoltaic applications is the prediction of electric behavior concerning a photovoltaic generator, given that there exists the need for constructive information on the photovoltaic modules, the geographic location and the local climate that directly influence energy production. In order to bypass this difficulty, the photovoltaic generator will be modeled as a harmonic current source and the current injection value will vary according to the case for simulation, following the average monthly curves for energy production of the PVP. Figure 4 shows some examples of these energy production curves for the months of January, July and November of 2019. 

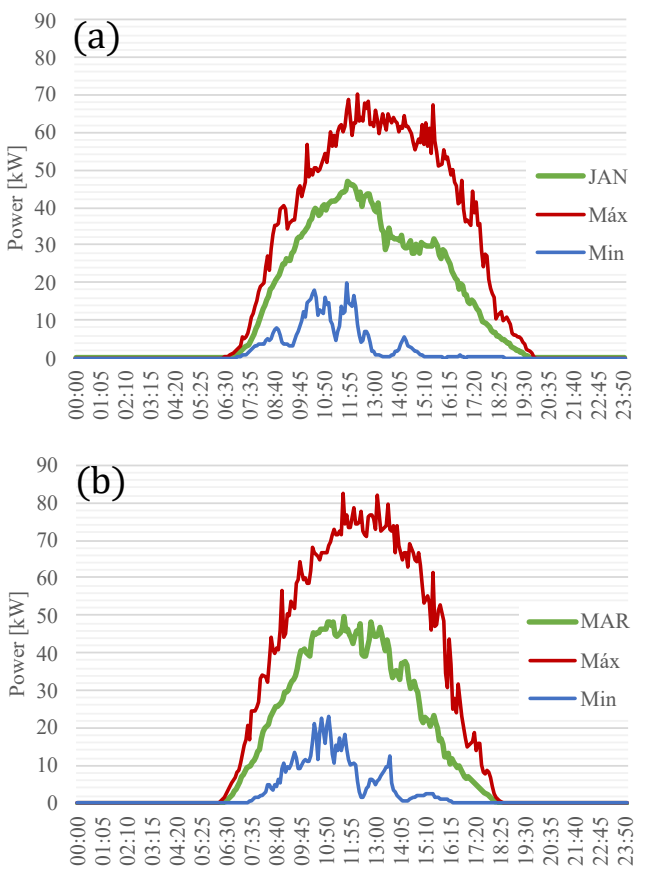
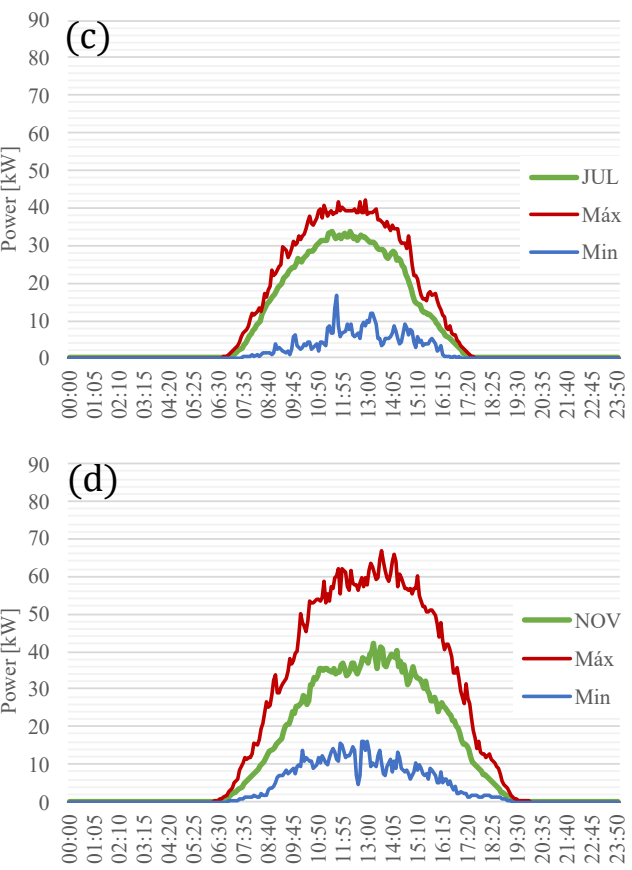

Figure 4. Average hourly production for (a) January, (b) March, (c) July and (d) November of 2019 from the PVP at the IFSULDEMINAS Campus Poços de Caldas. Noteworthy is the monthly hourly average and the maximum and minimum reported values over the period.

\subsection{Adjustments and Calibration of the Model}

In order to evaluate both models, the decision was made to set the simulations against measurements taken in the field. As such, demands, generation of solar photovoltaic power and the voltage levels were reported in a simultaneous fashion at the output of the main substation $\left(S E_{P C 3}\right)$ as well as at the grid connection point of the IFSULDEMINAS substation $\left(S E_{I F}\right)$. To this end, a Wednesday (16 January 2019), a Saturday (26 January 2019) and 17 July 2019-a Wednesday with the highest registered power demand over the period in question-were the days chosen.

Table 3 presents the data obtained with measurements and simulations, on January 16 and 26, only for the hybrid method model. It is noteworthy that in cases 01 and 02, the grid model was configured for the photovoltaic generation peak and, in the others, for the feeder power demand peak. Also in Table $3, P_{F V}$ indicates the photovoltaic plant instantaneous power; $D_{I F}$ and $D_{A L 19}$ are, respectively, the demands of IFSULDEMINAS and feeder 19; $V_{S E_{P C 3}}$ and $V_{S E_{I F}}$ are the bus voltages at main $\left(S E_{P C 3}\right)$ and IFSULDEMINAS $\left(S E_{I F}\right)$ substations, respectively.

Table 3. Synthesis of data for the computational model validation for proposed hybrid method.

\begin{tabular}{ccccccccccccc}
\hline & \multicolumn{3}{c}{ Input Data } & \multicolumn{4}{c}{ Measured Data } & \multicolumn{3}{c}{ Simulated Data } \\
\hline Case & \multirow{2}{*}{ Day } & Hour & $\begin{array}{c}\boldsymbol{P}_{F V} \\
{[\mathbf{k W}]}\end{array}$ & $\begin{array}{c}\boldsymbol{D}_{I F} \\
{[\mathbf{k W}]}\end{array}$ & $\begin{array}{c}\boldsymbol{D}_{A L 19} \\
{[\mathbf{k W}]}\end{array}$ & $\begin{array}{c}\boldsymbol{V}_{S E_{P C 3}} \\
{[\mathbf{p u}]}\end{array}$ & $\begin{array}{c}\boldsymbol{V}_{S E_{I F}} \\
{[\mathbf{p u}]}\end{array}$ & $\begin{array}{c}\boldsymbol{V}_{S E_{P C 3}} \\
{[\mathbf{p u}]}\end{array}$ & $\begin{array}{c}\text { Error } \\
{[\%]}\end{array}$ & $\begin{array}{c}\boldsymbol{V}_{S E_{I F}} \\
{[\mathbf{p u}]}\end{array}$ & $\begin{array}{c}\text { Error } \\
{[\%]}\end{array}$ \\
\hline 01 & 16.01 & $12 \mathrm{~h} 45$ & 54.43 & 0 & 2177.28 & 1.028 & 1.023 & 1.028 & 0.0000 & 1.02298 & 0.0020 \\
02 & 26.01 & $15 \mathrm{~h} 30$ & 52.56 & 0 & 2217.60 & 1.046 & 1.027 & 1.046 & 0.0000 & 1.02934 & 0.2240 \\
\hline 03 & 16.01 & $19 \mathrm{~h} 45$ & 0 & 9.74 & 3507.84 & 1.037 & 1.017 & 1.037 & 0.0000 & 1.0210 & 0.3933 \\
04 & 26.01 & $19 \mathrm{~h} 45$ & 0 & 9.41 & 3528.00 & 1.046 & 1.031 & 1.046 & 0.0000 & 1.0300 & 0.0970 \\
\hline
\end{tabular}

In turn, the Figure 5, presents the results obtained with the measurements and simulations for the $24 \mathrm{~h}$ of the 17th of July and compares the response of both models. The percentage error between simulated values and measured values is presented as a bar chart. 


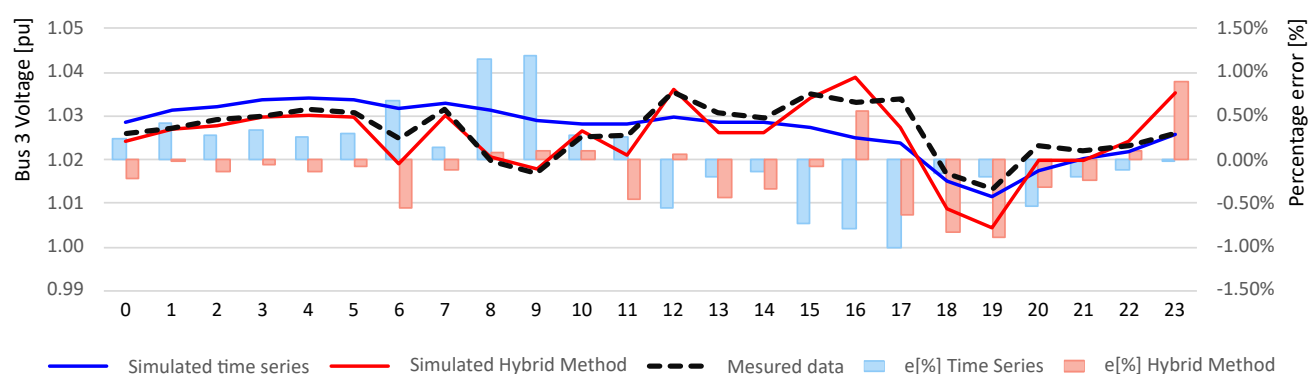

Figure 5. Voltages at bus 3 throughout the day 17th of July 2019: Comparison between measured and simulated values.

Thus, both from the Table 3 and the Figure 5, it appears that the simulation follows the expected behavior, replicating the measured data for the cases studied. It is also verified that the percentage errors presented in the Figure 5, are, in general, below $1.0 \%$ and, therefore, it can be said that the network modeling it is suitable for carrying out the desired studies and reported in this work.

\section{The Hybrid Methodology Proposed for Determining HC}

As defined in [11], the grid hosting capacity (HC) for DG is not a fixed calculation with a singular result, i.e., it depends on the parameters analyzed (voltage variations and/or frequency, thermal overload, power quality and protection concerns) which, for this study, uses the limits defined by chapter 8 of PRODIST (Distribution Procedures) defined by ANEEL (Brazilian National Agency of Electrical Energy) [30].

However, according to [6], the increase in voltage is seen as the most prominent problem on a feeder, in addition the authors from [18,31] conclude that the problems associated with voltage regulation, due to excessive generation, are more likely to occur than other power quality problems, even at lower levels of PV penetration. As such, in this paper, the option was made for calculating the hosting capacity of the network, while discerning the voltage limits in steady state.

Hence, to calculate the grid hosting capacity based on voltage limits, the hybrid method proposes to save computational time by simulating the most critical scenario for the grid wich will always occurs with the the maximum PV generation and a low feeder loading. The identification of the scenario of interest is possible when combining the Figures 3 and 4 into Figure 6. One may observe that the peak of photovoltaic energy production (at $12 \mathrm{~h}$ ) does not coincide with the peak demand of the feeder $(19 \mathrm{~h})$.

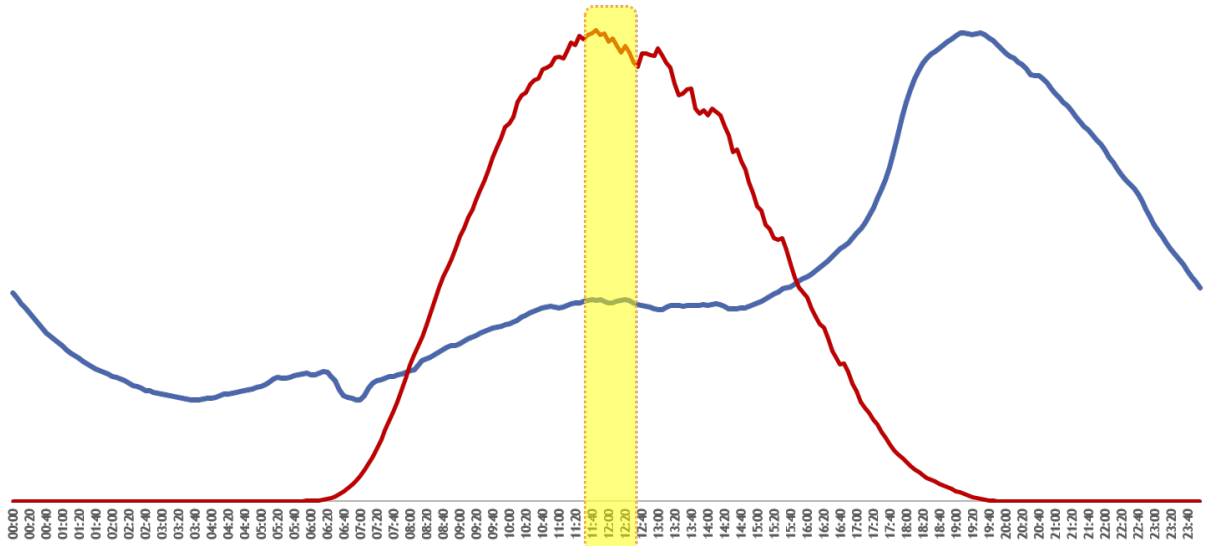

Figure 6. The identification of the scenario of interest is possible when overlapping and comparing the PV generation and the feeder loading charts.

Therefore, once set the hour and the parameter for analysis, the calculation process can be written in the form of the flowchart in Figure 7 where: $i$ denotes the buses that will 
have DG installed-Buses B1, B3, B5 and B6, see Figure 1-and $k$ indicates the PRODIST's parameter analyzed (in this case Long-duration Voltage Variation).

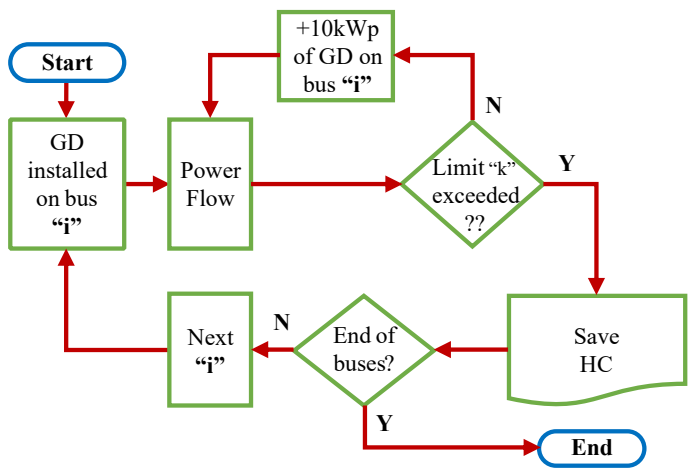

Figure 7. Simplified flowchart of the Hosting Capacity calculation.

\section{Results and Discussion}

The computational analysis performed is highlighted through the implementation of five cases. The first, denominated as "case 00 " in which the system does not count on any installed DG. In the cases that follow, PVP were added on previously selected buses, and the model dedicated to the hybrid method was configured for noon, that is, peak photovoltaic generation and low demand on feeder 19. Each case is compared with the time series model where a $24 \mathrm{~h}$ period was simulated. Next, the main obtained results are presented for each case analyzed and finally, the feeder hosting capacity is determined.

It should be noted that the study in question has not considered nor analyzed the impacts arising from small generating units installed on the rooftops of residential, commercial and industrial installations because, by the time when this work was conducted, there was no rooftops PVP in the feeder 19. However, each LV network that was presented as a concentrated load in this paper, will be investigated and is part of a work in progress whose results will be published in future work.

\subsection{Case 00}

Here, one notes the system running without any PVP installed. In this configuration, the buses voltages, at noon, are all between 1.016 and $1.031 \mathrm{pu}$ as can be seen in the Figure 8 . As expected, the voltage at bus $6\left(V_{B 6}\right)$ is the lowest since it is the farthest bus from the substation.

When observing the $24 \mathrm{~h}$ period, one sees the typical behavior of a predominantly residential radial feeder, where the highest voltages occur during the night and the lowest during the peak demand, which in this case occurs between $18 \mathrm{~h}$ and $19 \mathrm{~h}$.

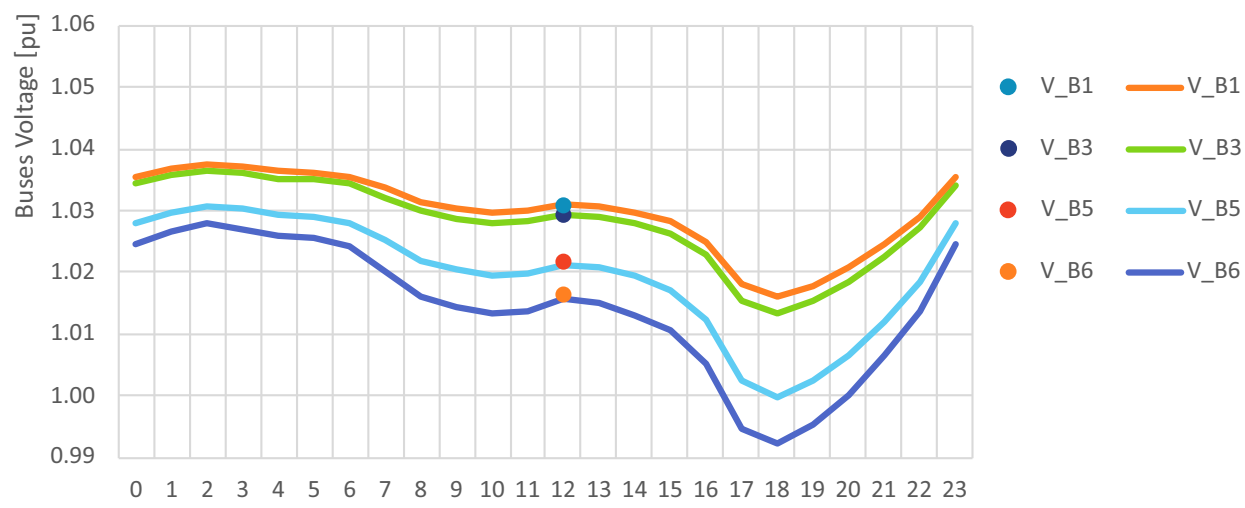

Figure 8. Case 00: Voltages in buses 6, 5,3 and 1. The curves are given by the time series method and the dots, by the proposed hybrid method. 


\subsection{Case 01}

In this scenario, the PVP will was installed on bus 6. The region where this bus is located is an area of municipal expansion, it possesses large open spaces for construction, and can serve projects linked to photovoltaic plants.

Following the steps indicated in Figure 7, it was determined that it is possible to install 2.3 MWp when the overvoltage limit of 1.05 pu established by PRODIST [30] was exceeded. It can be seen in the Figure 9 that the violation occurs at 12 p.m. at the PVP site, i.e., at bus 6 , as expected, and that the voltages at the other buses are around $1.04 \mathrm{pu}$.

It can also be observed when comparing the Figures 8 and 9 that the behavior of the voltage profile is changed with the insertion of the PVP at the end of the feeder.

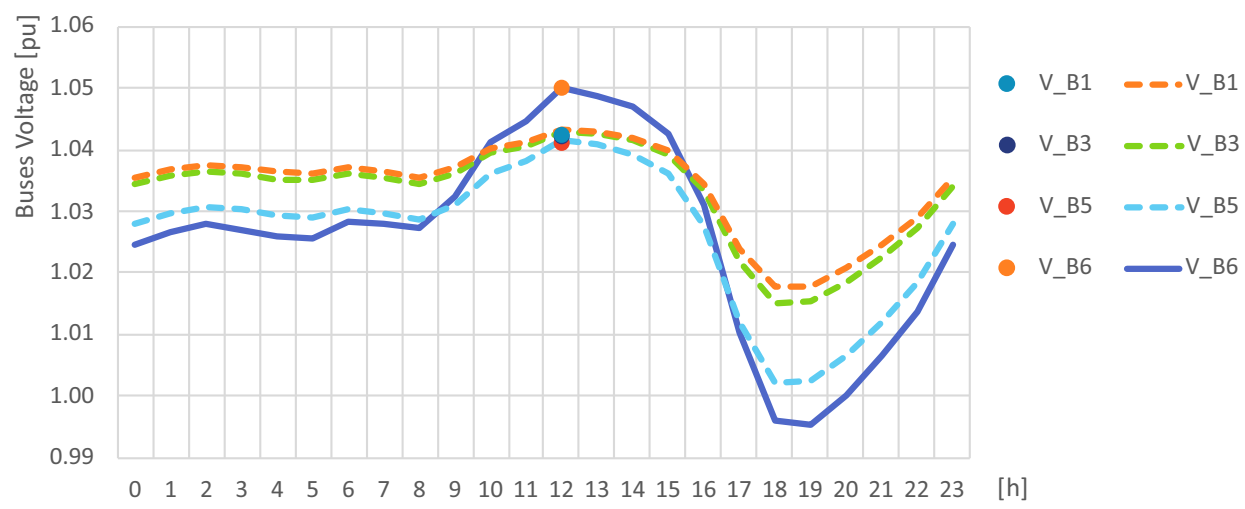

Figure 9. Case 01: PVP installed on bus 6 (indicated by the solid line in the graph). The curves are given by the time series method and the dots, by the proposed hybrid method.

\subsection{Case 02}

The PVP, in this case, was installed on bus 5. The bus is situated in a region of interest of the energy utility, as it is a region of a large middle class population, which is predominantly residential, and counts on a school, local market and other small commercial businesses.

Similar to the previous case, the upper voltage limit was also broken by the bus on which the PVP was installed, hosting a maximum of $3.5 \mathrm{MWp}$. In the Figure 10 it is again possible to observe that the other buses were also affected and had a voltage level close to $1.05 \mathrm{pu}$. This can be explained by the fact that Bus 5 is geographically close to the center of the feeder, impacting it more evenly.

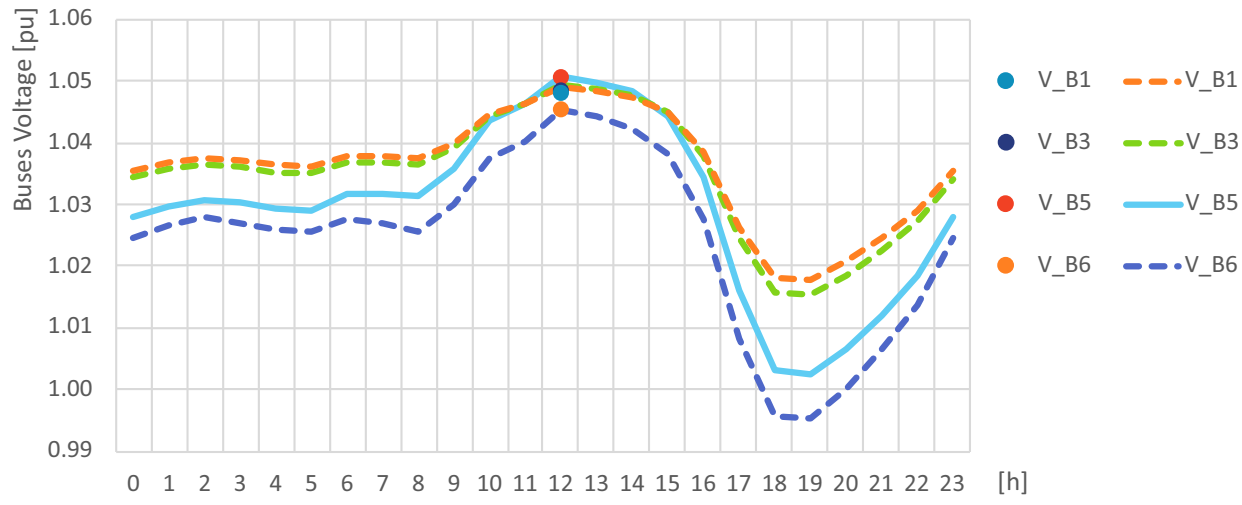

Figure 10. Case 02: PVP installed on bus 5 (indicated by the solid line in the graph). The curves are given by the time series method and the dots, by the proposed hybrid method.

\subsection{Case 03}

The case in question, presents bus 3 that serves a medium voltage consumer (IFSULDEMINAS) who already has a PVP installed. Within the current Brazilian legislation [32], this single consumer could expand its PVP up to 5.0 MWp. However, the upper 
voltage limit is already exceeded when a total of 3.8 MWp is installed in this bus, as can be seen in the Figure 11. Still in the figure, it can be seen that buses 5 and 6 were not affected as much as buses 3 and 1, although they still show a voltage rise.

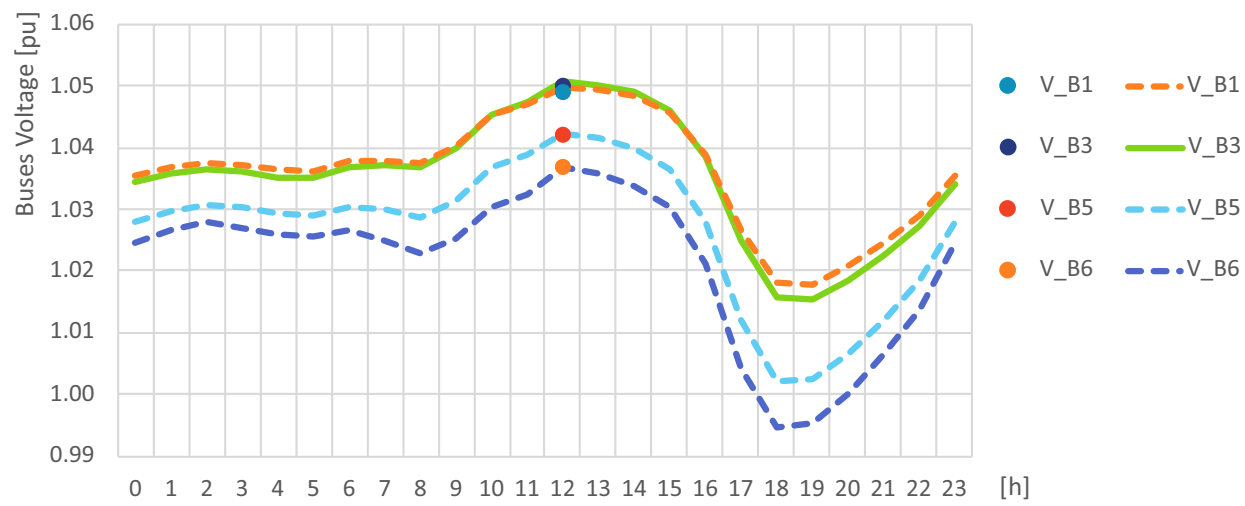

Figure 11. Case 03: PVP installed on bus 3 (indicated by the solid line in the graph). The curves are given by the time series method and the dots, by the proposed hybrid method.

\subsection{Case 04}

In this scenario, the PVP was installed on bus 1 which is closest to the main substation $\left(S E_{P C 3}\right)$. The neighborhood in the vicinity is similar to case 2, i.e., with a large population density, predominantly residential but with schools, local market and other commercial points.

Thus, the grid reach the hosting Capacity at 3.9 MWp of DG installed on this bus. As in the previous case, it can be seen that buses 5 and 6 were not as affected as buses 1 and 3, as can be seen in the Figure 12.

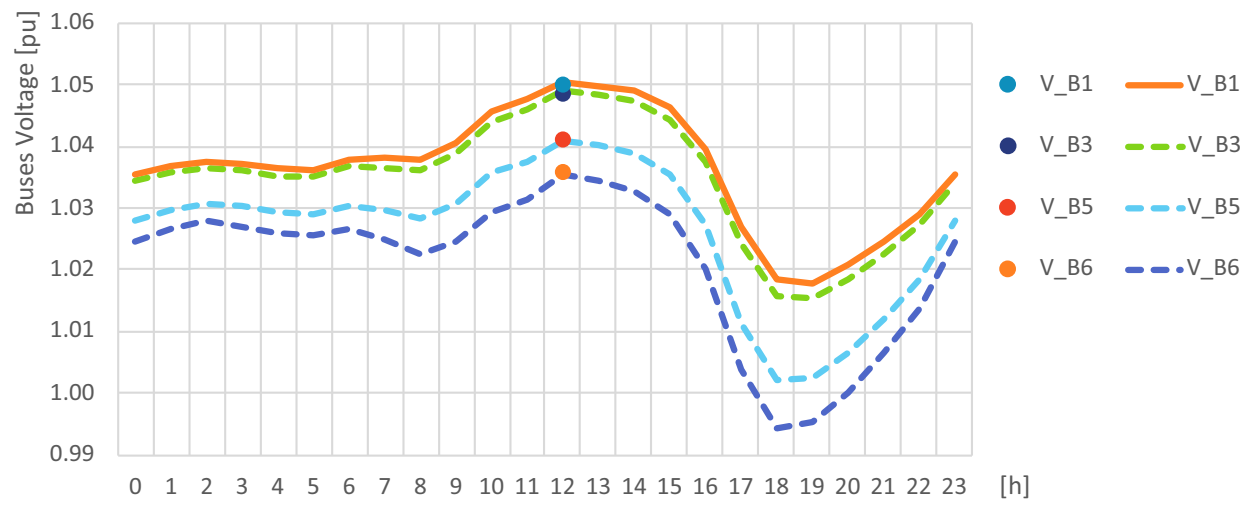

Figure 12. Case 04: PVP installed on bus 1 (indicated by the solid line in the graph). The curves are given by the time series method and the dots, by the proposed hybrid method.

In order to better compare the results between the time series methodology and the proposed hybrid methodology, Table 4 shows the obtained results and the percent variance related to the hybrid method. It is noteworthy that the variation between them was below $0.1 \%$. In the cases presented, one can see that the proposed methodology reached the same values, with a smaller number of simulated cases. 
Table 4. Comparative between applied methodologies: Buses voltages at 12 p.m.

\begin{tabular}{|c|c|c|c|c|}
\hline & & $\begin{array}{c}\text { Time Series } \\
\text { Method } \\
\text { [pu] }\end{array}$ & $\begin{array}{c}\text { Proposed } \\
\text { Hybrid Method } \\
\text { [pu] }\end{array}$ & $\Delta \%$ \\
\hline \multirow{4}{*}{ Case 00} & $V_{B 6}$ & 1.0156 & 1.0164 & $-0.075 \%$ \\
\hline & $V_{B 5}$ & 1.0212 & 1.0217 & $-0.050 \%$ \\
\hline & $V_{B 3}$ & 1.0293 & 1.0293 & $-0.004 \%$ \\
\hline & $V_{B 1}$ & 1.0309 & 1.0309 & $0.005 \%$ \\
\hline \multirow{4}{*}{ Case 01} & $V_{B 6}$ & 1.0501 & 1.0501 & $0.000 \%$ \\
\hline & $V_{B 5}$ & 1.0414 & 1.0411 & $0.030 \%$ \\
\hline & $V_{B 3}$ & 1.0430 & 1.0422 & $0.077 \%$ \\
\hline & $V_{B 1}$ & 1.0434 & 1.0424 & $0.087 \%$ \\
\hline \multirow{4}{*}{ Case 02} & $V_{B 6}$ & 1.0453 & 1.0453 & $-0.018 \%$ \\
\hline & $V_{B 5}$ & 1.0507 & 1.0506 & $0.004 \%$ \\
\hline & $V_{B 3}$ & 1.0492 & 1.0485 & $0.070 \%$ \\
\hline & $V_{B 1}$ & 1.0490 & 1.0481 & $0.085 \%$ \\
\hline \multirow{4}{*}{ Case 03} & $V_{B 6}$ & 1.0368 & 1.0369 & $-0.006 \%$ \\
\hline & $V_{B 5}$ & 1.0423 & 1.0421 & $0.017 \%$ \\
\hline & $V_{B 3}$ & 1.0506 & 1.0500 & $0.060 \%$ \\
\hline & $V_{B 1}$ & 1.0498 & 1.0490 & $0.077 \%$ \\
\hline \multirow{4}{*}{ Case 04} & $V_{B 6}$ & 1.0355 & 1.0359 & $-0.033 \%$ \\
\hline & $V_{B 5}$ & 1.0410 & 1.0411 & $-0.010 \%$ \\
\hline & $V_{B 3}$ & 1.0489 & 1.0485 & $0.035 \%$ \\
\hline & $V_{B 1}$ & 1.0505 & 1.0500 & $0.045 \%$ \\
\hline
\end{tabular}

With the obtained results at hand, one can even define an index for Photovoltaic Penetration $\left(\operatorname{Pen}_{P V}[\%]\right)$, as a percentage of feeder maximum demand as defined in [33], as shown in Equation (3):

$$
\operatorname{Pen}_{P V}[\%]=\frac{P_{P V P}^{p}}{\max \left(D_{F}\right)} \cdot 100 \%
$$

where $P_{P V P}^{p}$ is the nominal peak power of the solar photovoltaic plant and $\max \left(D_{F}\right)$ is the feeder maximum power demand.

Thus, adopting $\max \left(D_{F}\right)$ equal to $4576.32 \mathrm{~kW}$-as shown in Table 3-then penetration rates of $51.4 \%, 76.5 \%, 81 \%$ and $85.7 \%$ were obtained respectively. Which is in line with the postulate by Kharrazi, Sreeram and Mishra [18] showing that possible voltage regulation problems due to over-generation can occur even at lower penetration levels.

Therefore, it is concluded that the study carried out reveals that the feeder in focus has space for integration of distributed generation, however, one must pay attention to the grid connection region because, the distance between the connection bus and main substation will influence all other buses, as noted. In other words, connection at bus 1 is preferred, followed by buses 3,5 and finally at 6 . As a beneficial side effect, as long as the grid operation limits are respected, there is an improvement in the voltage level at the end of the feeder during the PVP's operating period.

In short, the hybrid method presented, used just one time series with the feeder power demand data, which are easily obtained from the feeder's origin substation. Low voltage loads were modeled by the ratio between their maximum demands and the feeder maximum demand, making easier to start up the grid model implementation. It should be noted that if data collection directly from consumer's smart meters is available, the load modeling suggested by the hybrid methodology could easily be refined to accommodate this new layer of information.

Bearing in mind the operational difficulties of Brazilian utilities, which have seen the number of connections to their grids grow exponentially year after year [4], one can see 
that to simulate only the critical point of the system through the proposed methodology, allows to speed up the analysis and, consequently, the process to release the integration of new PVPs.

It is noteworthy that analyzes with large feeders, such as 880,1760 and 4400 nodes [16,34], were not the focus of this work. However, the expansion of the proposed methodology to feeders with these configurations is planned for future work.

Hence, the advantages of the proposed methodology can be summarized in: (a) easy to obtain the input parameters; (b) agility in implementing the study; (c) higher processing speed and $(\mathrm{d})$ results consistent with the time series method.

Once again, it should be noted that the study in question has not considered the impacts arising from small rooftops PVP because, by the time when this work was conducted, there was no rooftops PVP in the feeder 19. However, each LV network that was presented as a concentrated load in this paper (see Figure 2), will be investigated and is part of a work in progress whose results will be published in future work.

Finally, in view of the aforementioned advantages and the efficiency presented by the method, the proposed hybrid methodology shows itself as a promising and attractive tool for the studies of hosting capacity by the utilities.

Author Contributions: E.J.L. and L.C.G.F. were involved throughout the study of this research work. All authors have read and agreed to the published version of the manuscript.

Funding: This research was funded by "IFSolares R\&D Project" a partnership between ANEEL, DMED and IFSULDEMINAS Campus Poços de Caldas, grant number ANEEL-PD-00051-0217/2017 and in part by Brazilian Federal University of Uberlândia (UFU) and in part by FAPEMIG (Process number TEC-PPM-00485-17).

Acknowledgments: The authors would like to thank the energy utility DMED and IFSULDEMINAS for their support and attention. They also thank FAPEMIG and UFU for funding this paper publication.

Conflicts of Interest: The funders had no role in the design of the study; in the collection, analyses, or interpretation of data; in the writing of the manuscript, or in the decision to publish the results.

\section{Abbreviations}

The following abbreviations are used in this manuscript:

$\begin{array}{ll}\text { ANEEL } & \text { Brazilian National Agency of Electrical Energy } \\ \text { DG } & \text { Distributed Generation (also called Decentralized Generation) } \\ \text { HC } & \text { Hosting Capacity } \\ \text { IFSULDEMINAS } & \begin{array}{l}\text { Brazilian Federal Institute of Education, Science and Technology of south of } \\ \text { Minas Gerais }\end{array} \\ \text { MG } & \text { Brazilian State of Minas Gerais } \\ \text { PRODIST } & \text { Distribution Procedures from ANEEL } \\ \text { PVP } & \text { Photovoltaic plant (solar photovoltaic power plant) } \\ \text { SE } & \text { Electrical substation }\end{array}$

\section{References}

1. Masson, G.; Kaizuka, I. Trends in Photovoltaic Applications 2019, 2019 ed.; IEA: Paris, France, 2019; p. 100. Available online: www.iea-pvps.org/publications / (accessed on 27 January 2022).

2. EPE. Balanço Energético Nacional 2019—Relatório Síntese Ano Base 2018; Technical Report; EPE: Rio de Janeiro, Brazil, 2019. Available online: www.epe.gov.br/pt/publicacoes-dados-abertos/publicacoes/balanco-energetico-nacional-2019 (accessed on 27 January 2022).

3. EPE. Balanço Energético Nacional 2020: Ano base 2019; EPE: Rio de Janeiro, Brazil, 2020; p. 264. Available online: https: //www.epe.gov.br/pt/publicacoes-dados-abertos/publicacoes/balanco-energetico-nacional-2020 (accessed on 27 January 2022).

4. ABSOLAR. Infográfico da Energia Solar Fotovoltaica no Brasil; Technical Report; ABSOLAR: São Paulo, Brazil, 2021. Available online: www.absolar.org.br/mercado/infografico/ (accessed on 27 January 2022). 
5. ANEEL/SPE. CHAMADA N No. 001/2016 PROJETO PRIORITÁRIO DE EFICIÊNCIA ENERGÉTICA E ESTRATÉGICO DE PED: “EFICIÊNCIA ENERGÉTICA E MINIGERAÇÃO EM INSTITUIÇÕES PÚBLICAS DE EDUCAÇÃO SUPERIOR”; Technical Report; ANEEL: Brasília, Brazil, 2016. Available online: http:/ / bit.ly/38C2CP1 (accessed on 27 January2022).

6. Karimi, M.; Mokhlis, H.; Naidu, K.; Uddin, S.; Bakar, A.H. Photovoltaic penetration issues and impacts in distribution network-A review. Renew. Sustain. Energy Rev. 2016, 53, 594-605. [CrossRef]

7. Chathurangi, D.; Jayatunga, U.; Rathnayake, M.; Wickramasinghe, A.; Agalgaonkar, A.; Perera, S. Potential power quality impacts on LV distribution networks with high penetration levels of solar PV. In Proceedings of the 201818 th International Conference on Harmonics and Quality of Power (ICHQP), Ljubljana, Slovenia, 13-16 May 2018; pp. 1-6. [CrossRef]

8. Joint Working Group C4.24/CIRED. Power Quality and EMC Issues with Future Electricity Networks; Technical Report; CIGRÉ: Paris, France, 2018. Available online: www.cired.net/uploads/default/files/final-report-C4.24-CIRED.pdf (accessed on 27 January 2022).

9. EPRI. Impact Factors, Methods, and Considerations for Calculating and Applying Hosting Capacity; Technical Report; EPRI: Palo Alto, CA, USA, 2018.

10. Barin, A.; Felipe Pozzatti, L.; Quadros Machado, R.; Neves Canha, L.; Alberto Farret, F.; da Rosa Abaide, A. Multicriteria Analysis of Impacts of Distributed Generation Sources On Operational Network Characteristics For Distribution System Planning Concerning Steady-State And Transient Operations. Eletrônica de Potência 2009, 14, 75-83. [CrossRef]

11. Ismael, S.M.; Abdel Aleem, S.H.; Abdelaziz, A.Y.; Zobaa, A.F. State-of-the-art of hosting capacity in modern power systems with distributed generation. Renew. Energy 2019, 130, 1002-1020. [CrossRef]

12. Mulenga, E.; Bollen, M.H.; Etherden, N. A review of hosting capacity quantification methods for photovoltaics in low-voltage distribution grids. Int. J. Electr. Power Energy Syst. 2020, 115, 105445. [CrossRef]

13. Koirala, A.; Van Acker, T.; D’hulst, R.; Van Hertem, D. Hosting capacity of photovoltaic systems in low voltage distribution systems: A benchmark of deterministic and stochastic approaches. Renew. Sustain. Energy Rev. 2022, 155, 111899. [CrossRef]

14. Zain ul Abideen, M.; Ellabban, O.; Al-Fagih, L. A Review of the Tools and Methods for Distribution Networks' Hosting Capacity Calculation. Energies 2020, 13, 2758. [CrossRef]

15. Zhang, Y.; Shi, X.; Zhang, H.; Cao, Y.; Terzija, V. Review on deep learning applications in frequency analysis and control of modern power system. Int. J. Electr. Power Energy Syst. 2022, 136, 107744. [CrossRef]

16. Roberge, V.; Tarbouchi, M.; Okou, F.A. Distribution System Optimization on Graphics Processing Unit. IEEE Trans. Smart Grid 2017, 8, 1689-1699. [CrossRef]

17. Munikoti, S.; Abujubbeh, M.; Jhala, K.; Natarajan, B. A novel framework for hosting capacity analysis with spatio-temporal probabilistic voltage sensitivity analysis. Int. J. Electr. Power Energy Syst. 2022, 134, 107426. [CrossRef]

18. Kharrazi, A.; Sreeram, V.; Mishra, Y. Assessment techniques of the impact of grid-tied rooftop photovoltaic generation on the power quality of low voltage distribution network-A review. Renew. Sustain. Energy Rev. 2020, 120, 109643. [CrossRef]

19. Arshad, A.; Lehtonen, M. A Stochastic Assessment of PV Hosting Capacity Enhancement in Distribution Network Utilizing Voltage Support Techniques. IEEE Access 2019, 7, 46461-46471. [CrossRef]

20. Arshad, A.; Lehtonen, M. Probabilistic Assessment of Photovoltaic Hosting Capacity in Finnish LV Networks. In Proceedings of the 2019 IEEE PES Innovative Smart Grid Technologies Europe (ISGT-Europe), Bucharest, Romania, 29 September-2 October 2019; pp. 1-5. [CrossRef]

21. Von Zuben, F.J. Fundamentos para Processos Estocásticos; Technical Report; UNICAMP: Campinas, Brazil, 2003.

22. Gontijo, R.M.P. Alocação de Geradores Distribuídos Orientada por Fluxo de Potência Probabilístico. Bachelor's Thesis, UFOP, João Monlevade, Brazil, 2017. Available online: http:/ / www.monografias.ufop.br/handle/35400000/860 (accessed on 27 January 2022).

23. de Paula Silva, S.F. SSEP: Simulador de Sistemas Elétricos de Potência, 4.0.0.25 ed.; Quality Engenharia \& Sistemas: Uberlândia, Brazil, 2016.

24. Dugan, R.C.; Montenegro, D.; Ballanti, A. Reference Guide: The Open Distribution System Simulator (OpenDSS); EPRI: Palo Alto, CA, USA, 2020; pp. 1-218.

25. Kagan, N.; Robba, E.J.; Schmid, H.P. Estimação de indicadores de qualidade da energia elétrica, 1st ed.; Blucher: São Paulo, Brazil, 2009.

26. Jardini, J.; Tahan, C.; Gouvea, M.; Ahn, S.; Figueiredo, F. Curvas de Carga Típicas e Agregação dos Consumidores Residenciais, Comerciais e Industriais de Baixa Tensão. In 4to Encontro Luso-Afro-Brasileiro de Planjamento e Exploraçao de Redes de Energia-ELAB; ELAB: Rio de Janeiro, Brazil, 1999; pp. 391-397.

27. Marques, M.D.S. Metodologia para Modelagem de Curvas Típicas de Demanda Elétrica Utilizando Redes Neurais Artificiais Considerando Variáveis Climáticas. Dissertação Thesis, Universidade Federal do Pampa, Bagé, Brazil, 2014.

28. Paula, G.M.d.F. Curvas típicas de carga para o planejamento operacional do sistema de distribuição. Ph.D. Thesis, USP, São Paulo, Brazil, 2006.

29. Sauthier, L.F.; Diefenthäler, A.T.; Sausen, P.S.; Sausen, A.T.Z.R. MODELAGEM MATEMÁTICA DE MÓDULOS FOTOVOLTAICOS EMPREGADOS EM AMBIENTES DE SIMULAÇÃO DE GERAÇÃO DISTRIBUÍDA. In 11th SEMINAR ON POWER ELECTRONICS AND CONTROL; UFSM: Santa Maria, Brazil, 2018; p. 6. Available online: www.ufsm.br/app/uploads/sites/553/2020/07/ 92898-field_submission_abstract_file2.pdf (accessed on 27 January 2022). 
30. ANEEL. Módulo 8 - Qualidade da Energia Elétrica. In Procedimentos de Distribuição de Energia Elétrica no Sistema Elétrico Nacional-PRODIST, 10th ed.; Agência Nacional de Energia Elétrica: Brasilia, Brazil, 2018; Chapter 8, p. 88. Available online: https:/ / www.aneel.gov.br/documents /656827/14866914/M\%C3\%B3dulo_8-Revis\%C3\%A3o_10/2f7cb862-e9d7-3295-72 9a-b619ac6baab9\%20 (accessed on 27 January 2022).

31. Liu, D.; Wang, C.; Tang, F.; Zhou, Y. Probabilistic assessment of hybrid wind-PV hosting capacity in distribution systems. Sustainability 2020, 12, 2183. [CrossRef]

32. ANEEL. Resolução Normativa $n^{\circ} 482$ de 17 de Abril de 2012; ANEEL: Brasilia, Brazil, 2012; p. 1. Available online: http://www2 .aneel.gov.br/cedoc/atren2012482.pdf (accessed on 27 January 2022).

33. Kordkheili, R.A.; Bak-Jensen, B.; R-Pillai, J.; Mahat, P. Determining maximum photovoltaic penetration in a distribution grid considering grid operation limits. In Proceedings of the 2014 IEEE PES General Meeting I Conference \& Exposition, National Harbor, MD, USA, 27-31 July 2014; pp. 1-5. [CrossRef]

34. Roberge, V. Distribution Feeder Reconfiguration (DFR) Test Cases. 2021. Available online: https://roberge.segfaults.net/joomla/ index.php/dfr (accessed on 27 January 2022). 